\title{
Survival of Advanced Stage High-Grade Serous Ovarian Cancer Patients in the Republic of Macedonia
}

\author{
Igor Aluloski ${ }^{*}$, Mile Tanturovski ${ }^{1}$, Rubens Jovanovic ${ }^{2}$, Slavica Kostadinova-Kunovska ${ }^{2}$, Gordana Petrusevska ${ }^{2}$, Igor \\ Stojkovski ${ }^{3}$, Bojana Petreska ${ }^{3}$ \\ ${ }^{1}$ Department of Gynecologic Oncology, University Clinic of Gynecology and Obstetrics, Faculty of Medicine, Ss Cyril and \\ Methodius University of Skopje, Skopje, Republic of Macedonia; ${ }^{2}$ Institute of Patology, Faculty of Medicine, Ss Cyril and \\ Methodius University of Skopje, Skopje, Republic of Macedonia; ${ }^{3}$ University Clinic for Oncology and Radiotherapy, Faculty of \\ Medicine, Ss Cyril and Methodius University of Skopje, Skopje, Republic of Macedonia
}

\begin{abstract}
Citation: Aluloski I, Tanturovski M, Jovanovic R, Kostadinova-Kunovska S, Petrusevska G, Stojkovski Petreska B. Survival of Advanced Stage High-Grad Serous Ovarian Cancer Patients in the Republic of 15; https://doi.org/10.3889/oamjms.2017.215 Keywords: Ovarian cancer; High grade; Survival; Surgical cytoreduction

"Correspondence: Igor Aluloski. Department of Gynecologic Oncology, University Clinic of gynaecology and obstetrics, University "Ss. Cyril and Methodis", Received: 20-Aug-2017; Revised: 12-Oct-2017 Accepted: 28-Aug-2017; Revis: 20-Nov-2017 Copyright: (c) 2017 Igor Aluloski, Mile Tanturovski, Rubens Jovanovic, Slavica Kostadinova-Kunovska, Gordana Petrusevska, Igor Stojkovski, Bojana Petreska. This is an open-access article distributed under the term (CC BY-NC 4.0).

Funding: This research did not receive any financia

Competing Interests: The authors have declared that no competing interests exis.
\end{abstract}

\section{Abstract}

AIM: The primary objective of the study was to evaluate the overall survival of women with advanced stage (Stage IIIA-IV) high-grade serous ovarian cancer in Macedonia

MATERIALS AND METHODS: The study was a cross-sectional medical record review of patients diagnosed with advanced stage HGSC. Patients were deemed eligible for inclusion if they were diagnosed with an advanced stage (Stage IIIA-IV) HGSC of the ovary, fallopian tube or peritoneum between 2009 and 2015. The data were analyzed in a descriptive fashion and summary statistics were provided, as appropriate. Survival was calculated using the Kaplan-Meier method.

RESULTS: A total of 81 eligible patients were identified and included in the study. The average overall survival in the studied cohort was 46.59 months $(95 \% \mathrm{Cl}=39.11-54.06)$. Patients that were optimally debulked and patients that had a platinum-free interval larger than 12 months had significantly longer survival in the current series $(p<$ 0.001).

CONCLUSION: the average overall survival of advanced stage HGSC patients in the studied series was 46.59 months $(95 \% \mathrm{Cl}=39.11-54.06)$. Patients aged 65 years or younger tended to live approximately ten months longer than patients older than 65 years, but this difference was not statistically significant. There was no difference in HGSC survival in the groups of patients with grade 2 and grade 3 disease. However, optimal surgical debulking and platinum sensitivity were associated with significantly better overall survival.

\section{Introduction}

Epithelial ovarian cancer is the fifth most common cancer-related cause of death in women in the developed countries with no significant improvement in the survival rates in the last three decades in spite of numerous scientific efforts [1]. It is estimated that in Europe alone, a total of 65538 new cases and 42704 deaths were registered in 2012 [2]. Early stage disease (i.e. disease localised to the ovaries) is associated with an overall 5-year survival rate of over $90 \%$; however, only a small proportion of patients (approximately 15\%) present with early disease [3]. On the other hand, five-year survival rates for patients with metastatic ovarian cancer are currently estimated to be less than $30 \%$ [3]. The current consensus is that all patients with advanced or metastatic ovarian cancer should be treated with surgical debulking and subsequent systemic chemotherapy. First-line chemotherapy is usually a platinum-based regimen (i.e. carboplatin with or without paclitaxel) [4]. Most ovarian cancer patients have high initial response rates, but eventually, recur and require further treatment.

Tumor relapses can be classified, by the time interval between the completion of the initial platinumbased chemotherapy regimen and the diagnosis of the recurrence, as platinum-sensitive (recurrence detected after six months or longer) or platinumresistant (recurrence detected within six months). Patients with platinum-resistant tumours have poorer response rates to the subsequent chemotherapy regimens and, consequently, shorter overall survival [5]. Ovarian cancer may occur at any age, but most patients are older than 50 years at the time of diagnosis. Advanced age at the time of diagnosis is associated with poorer outcomes: the 5-year survival 
rate drops to below $30 \%$ in patients older than 65 years [6]. This is probably because older patients have at least one underlying comorbidity which is thought to be associated with poorer prognosis $[7,8]$.

The most common histological type of ovarian cancers is serous cancers. Once thought to arise from the ovarian surface epithelium, recent pathological and molecular studies have shifted the paradigm of the origin of serous epithelial ovarian cancers towards non-ovarian tissues, namely the secretory cells of the distal parts of the fallopian tubes [9].

Tumor grade, as a pathological index of cellular aberration, is an additional prognostic factor for serous ovarian cancer. It is widely accepted that low-grade tumours occur from tumours of borderline malignancy that acquire activating mutations in the member of the RAS pathway (KRAS, BRAF, and ErbB2) [10]. On the other hand, such mutations of the RAS pathway are rarely identified in high-grade serous cancers.

High-grade serous carcinomas (HGSCs) remain the most aggressive subtype of ovarian cancers and account for the vast majority of advanced stage cases [11].

To our knowledge, there is virtually no published data on the survival of advanced stage HGSC patients in the Republic of Macedonia. The primary objective of the study was to evaluate the overall survival of women with advanced stage (Stage IIIA-IV) high-grade serous ovarian cancer in Macedonia.

\section{Material and Methods}

The study was a cross-sectional medical record review of patients diagnosed with advanced stage HGSC. We searched the hospital registers of the University Clinic for gynaecology and obstetrics and the University clinic for oncology and radiotherapy at the University "Ss. Cyril and Methodius" in Skopje, Macedonia. Both participating academic centres are tertiary healthcare where the majority of these patients in Macedonia are referred for treatment. Patients were deemed eligible for inclusion if they were diagnosed with an advanced stage (Stage IIIA-IV) HGSC of the ovary, fallopian tube or peritoneum between 2009 and 2015. Patients with non-serous histology, borderline tumours, early-stage and low-grade serous subtypes, as well as patients with insufficient follow-up data were excluded from the study. Clinical and disease characteristics, including age at diagnosis, stage, residual disease after primary surgery, treatment history and recurrence history, were collected from the available medical records. All primary surgeries were performed at the Department of gynecologic oncology at the University clinic of gynaecology and obstetrics, and all patients received adjuvant chemotherapy at the University clinic of oncology and radiotherapy. Cytoreductive surgery was characterised as optimal if there was $\leq 1 \mathrm{~cm}$ of residual disease and suboptimal if $>1 \mathrm{~cm}$ of disease remained at the end of the surgical procedure. The National statistics office of the Republic of Macedonia mortality registry was accessed in April 2017 to acquire the exact date of death of all patients. The same date was used as a cut-off for the surviving patients.

The data were analysed in a descriptive fashion and summary statistics were provided, as appropriate. Survival was calculated using the KaplanMeier method. For survival comparison, patients were grouped based on age into two groups: (1) 65 years and younger; (2) older than 65 years. Patients were further stratified in relation to the initial platinum-free interval as: (1) highly platinum-sensitive (recurrence after at least 12 months after stopping the initial adjuvant platinum-based therapy); (2) partially platinum, sensitive (recurrence within 6-12 months); and platinum resistant (recurrence or progression within 6 months of the initial platinum-based therapy). Differences in survival were also evaluated for the groups of patients with grade 2 and grade 3 tumours. The Mantel-Cox log-rank method was used to test for statistically significant differences in the survival. All statistical calculations were done using IBM SPSS Statistics software package, version 23 . A probability value of $p \leq 0.05$ was considered significant.

\section{Results}

A total of 81 eligible patients were identified and included in the study. Table 1 summarises the demographic and clinical characteristics of the study group.

Table 1: Summary of patient characteristics

\begin{tabular}{|c|c|}
\hline Characteristic & \\
\hline Age (median, [range]) & 60 years [24-78] \\
\hline \multicolumn{2}{|l|}{ Tumor grade } \\
\hline $2(n, \%)$ & 26 (32.1\%) \\
\hline $3(n, \%)$ & 55 (67.9\%) \\
\hline \multicolumn{2}{|l|}{ Tumor stage } \\
\hline IIIA $(n, \%)$ & $9(11.1 \%)$ \\
\hline $\operatorname{IIIB}(n, \%)$ & $24(29.6 \%)$ \\
\hline IIIC $(n, \%)$ & $45(55.6 \%)$ \\
\hline $\operatorname{IV}(n, \%)$ & $3(3.7 \%)$ \\
\hline \multicolumn{2}{|l|}{ Residual disease } \\
\hline$\leq 1 \mathrm{~cm}(n, \%)$ & $29(35.8 \%)$ \\
\hline$>1 \mathrm{~cm}(n, \%)$ & $52(64.2 \%)$ \\
\hline \multicolumn{2}{|l|}{ Platinum-free interval } \\
\hline$<6$ months & $16(19.8 \%)$ \\
\hline $6-12$ months & $24(29.6 \%)$ \\
\hline$>12$ months & $41(50.6 \%)$ \\
\hline
\end{tabular}

The median age of the patients was 60 years (range 24-78). Twenty-eight (34.6\%) patients were older than 65 years at the time of diagnosis. The majority of patients, 45 (55.6\%), were diagnosed with 
stage IIIC disease at the time of diagnosis, $9(11.1 \%)$ patients were staged as IIIA, $24(29.6 \%)$ patients had stage IIIB disease, and only $3(3.7 \%)$ patients were stage IV. All stage IV patients were classified as stage IV by malignant pleural effusion. Twenty-six (32.1\%) of the neoplasms were grade 2, and $55(67.9 \%)$ were grade 3. Optimal debulking was achieved in 29 patients $(35.8 \%)$. Forty-one $(50.6 \%)$ of the patients were reported to be highly platinum sensitive, with a platinum-free interval larger than 12 months. Thirty-six patients $(44.4 \%)$ from the cohort were still alive at the study cross-section point.

The average overall survival in the studied cohort was 46.59 months $(95 \% \mathrm{Cl}=39.11-54.06)$. Figure 1 shows the Kaplan-Meier survival function plot for the overall survival.

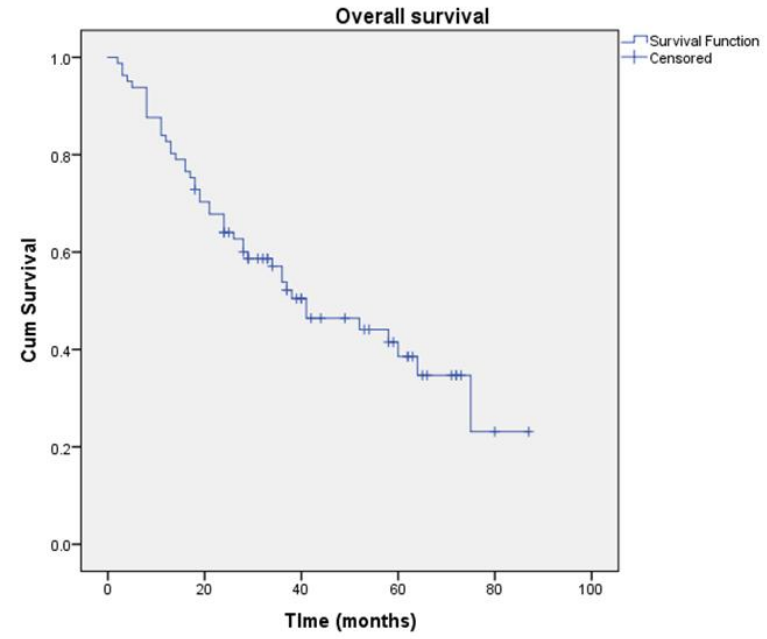

Figure 1: Overall survival of patients with an advanced stage highgrade serous cancer in the studied cohort

The estimated survival of patients 65 years old or younger was 49.18 months $(95 \% \mathrm{Cl}=40.85$ 57.51 ), compared to an average survival of 39.03 months $(95 \% \mathrm{Cl}=27.25-50.81)$ for patients older than 65 years (Figure 2), but the difference is not statistically significant $(p=0.099)$.

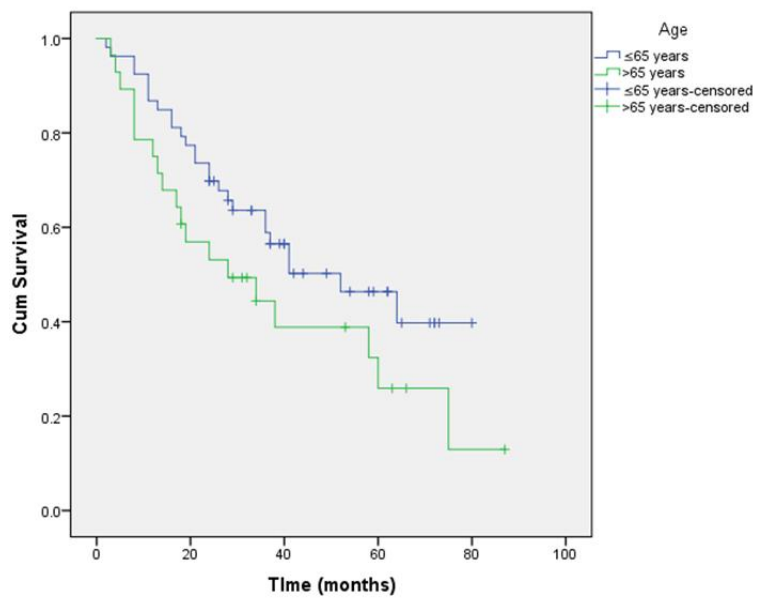

Figure 2: Comparison of survival in the different age groups
We also failed to document a statistically significant difference $(p=0.183)$ in the survival of patients with grade 2 and grade 3 disease, with survival averaging at 51.74 months $(95 \% \mathrm{Cl}=40.69$ $62.78)$ and 43.03 months $(95 \% \mathrm{Cl}=34.01-52.05)$ for grade 2 and grade 3 disease, respectively (Figure 3 ).

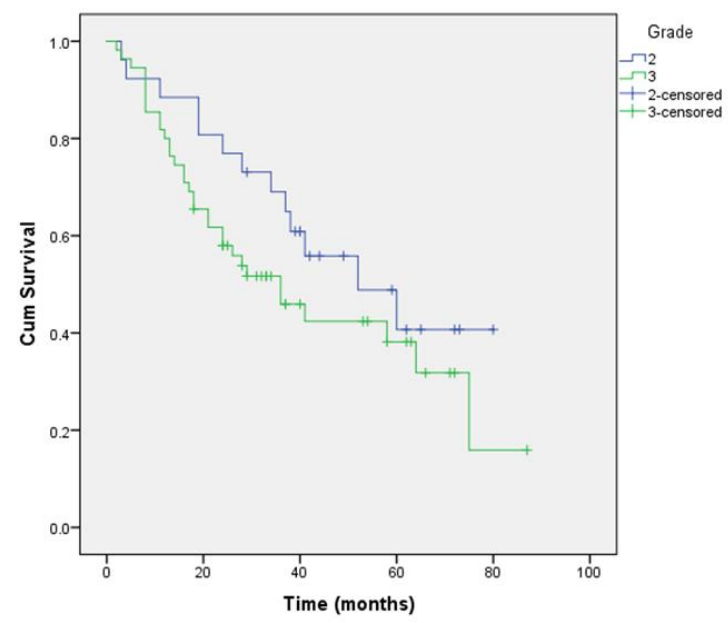

Figure 3: Comparison of survival in patients with grade 2 and grade disease

Optimal surgical debulking greatly influenced survival in the analysed series of patients. The estimated survival of patients that had the postoperative residual disease of $\leq 1 \mathrm{~cm}$ was 75.55 months $(95 \% \mathrm{Cl}=66.47-84.63)$, while patients with suboptimal surgical debulking (i.e. a postoperative residual disease of $>1 \mathrm{~cm}$ ) had an estimated survival of 30.78 months $(95 \% \mathrm{Cl}=24.14-37.42)(p<0.001)$.

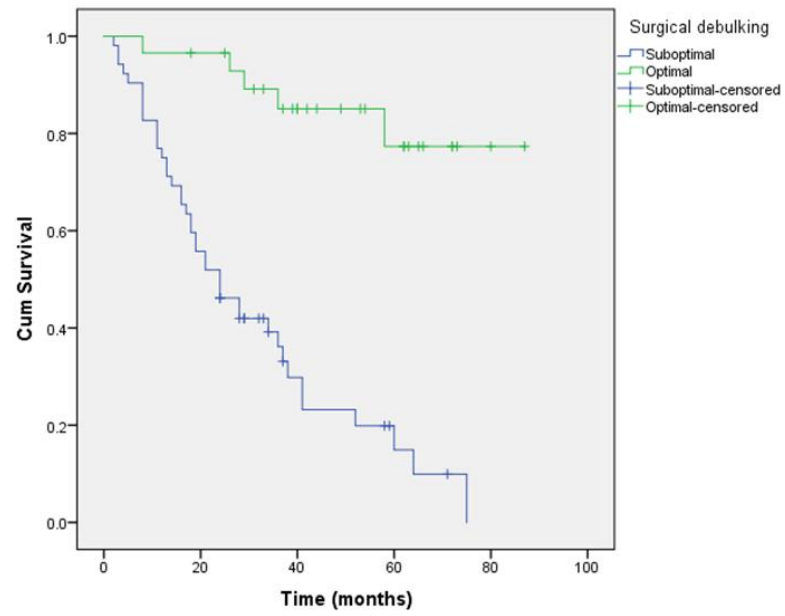

Figure 4: Comparison of survival in patients with optimal and suboptimal surgical debulking

Platinum sensitivity was also an important determinant of survival with estimated survival ranging from 8.75 months $(95 \% \mathrm{Cl}=6.55-10.95)$ for patients with a platinum-free interval less than 6 month, 27.89 months $(95 \% \mathrm{Cl}=23.38-32.39)$ for patients with a 
platinum-free interval of 6-12 months and 67.05 months $(95 \% \mathrm{Cl}=58.83-75.27)$ for highly platinumsensitive patients with a platinum-free interval longer than 12 months $(p<0.001)$. Figure 4 and 5 present the Kaplan-Meier plots for both comparisons.

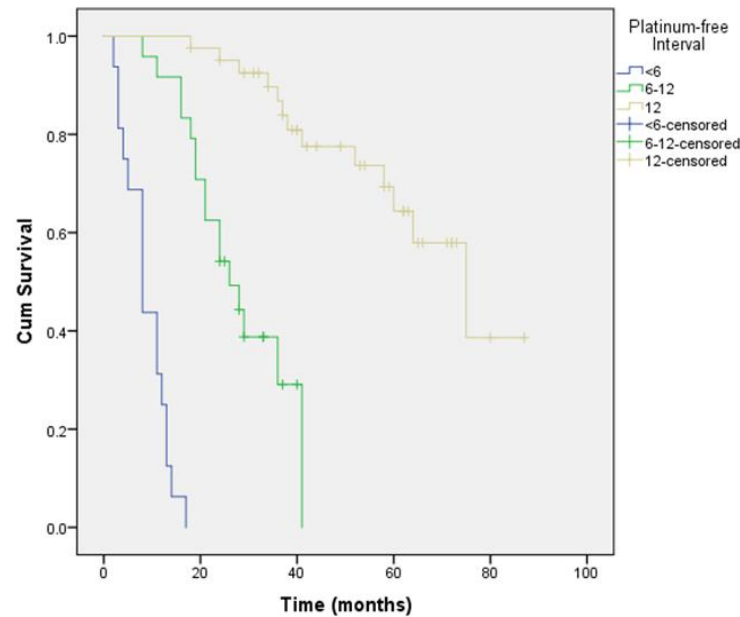

Figure 5: Comparison of survival depending on platinum resistance status

\section{Discussion}

In this study, we present the demographic and clinical (surgical and treatment-related) factors associated with survival in patients treated for advanced-stage HGSC in the Republic of Macedonia. We analysed the medical data of a total of 81 advanced stage HGSC patients. Patients with longer survival in our series appeared to be younger and were likely to have had optimal surgical cytoreduction, defined in the study as $\leq 1 \mathrm{~cm}$ of residual disease. Patients that had longer platinum-free intervals also had better survival rates. In spite of that, a small fraction of patients who either had suboptimal debulking or primary platinum resistance achieved paradoxically long survival periods.

Age has been consensually accepted as a prognostic factor for ovarian cancer survival [12, 13]. Older women have an increased risk of treatment failure and hence higher rates of recurrences and lower survival rates [14]. In the series of patients analysed by Markman et al. [15], the median survival for patients younger than 65 years was at least two years longer, compared to the median survival of patients older than 65 years. Patients in the current cohort that were older than 65 years had shorter average survival times of ten months, compared to patients younger than 65 years, but the difference was not statistically significant. The lack of statistical significance could be attributed to selection bias (advanced stage HGSC patients only) and a small sample size.

The tumour grade, or the degree of cellular differentiation, has long been considered a determinant of survival. The theory is based on the understanding that poorly differentiated cells manifest a higher degree of aberrant mitoses, which translates into a more aggressive cancer cell behaviour. However, published data for the association between tumour grade and clinical outcome are conflicting, partly as a result of the lack of a universally accepted grading system $[16,17]$. In the past decade, the wellestablished three-tier grading system introduced by FIGO in the 1970s that uses cellular architecture as the defining characteristic of tumour grade has been replaced by a two-tier system based on clinical, morphological and molecular studies [18, 19]. Indeed, our data showed no difference in survival between grades 2 and 3 , which was to be expected since all grade 2 and grade 3 tumours met contemporary criteria to be classified as high-grade tumours.

The success of cytoreductive surgery, defined by the volume of residual disease, has consistently been heralded as one of the most significant factors influencing both progression-free and overall survival [20]. In this study, optimal surgical debulking (defined as a residual disease of $\leq 1 \mathrm{~cm}$ ) more than doubled survival; patients that were optimally debulked had an estimated mean survival of 75.55 months versus and estimated mean survival of 30.78 months for patients with postoperative residual disease greater than $1 \mathrm{~cm}$ $(p<0.001)$. A Cochrane Database Review, published recently [21], was focused on analysing the effectiveness of optimal primary cytoreductive surgery in patients with advanced stage epithelial ovarian cancers. The authors demonstrated that overall survival and progression-free survival were significantly prolonged in patients who had no grossly visible residual disease following primary debulking surgery. The beneficial effects were also present in the groups of patients with residual diseases of less than $1 \mathrm{~cm}$, but only a borderline difference in progression-free survival remained when the residual disease of more and less than $2 \mathrm{~cm}$ was used as the basis for patient comparison. Consequently, the authors conclude that the aim of every primary surgery for advanced-stage epithelial ovarian cancer should be complete cytoreduction to no grossly visible disease.

One of the most reliable predictors of response to chemotherapy, and consequently survival, is the platinum-free interval $[15,22]$. This is mostly the result of the first-line adjuvant chemotherapy for ovarian cancers being relatively constant (carboplatin with paclitaxel) over the past two decades. Our data also showed that patients with a platinum-free interval longer than 12 months survived significantly longer $(p<0.001)$ when compared to patients with a platinum-free interval of 6-12 months and less than six months (67.05 months vs. 27.89 months and 8.75 months, respectively). 
The prognosis in ovarian cancer patients is largely a function of disease stage, which represents the most important prognostic variable for ovarian cancer survival. In the current series, we analysed only data from advanced stage patients, in an attempt to highlight the prognostic importance of other parameters such as tumour characteristics, surgical and treatment-related conditions and demographic factors. Furthermore, the study was descriptive. Recently published studies have focused on the significance of molecular features of the tumours as a proxy for tumour biology, thus enabling the researchers to better predict the response to various therapeutic modalities and determine factors influencing survival. Our future studies will compare this group of patients and compare survival by the molecular determinants of the tumour.

In conclusion, the average overall survival of advanced stage HGSC patients in the studied series was 46.59 months $(95 \% \mathrm{Cl}=39.11-54.06)$. Patients aged 65 years or younger tended to live approximately ten months longer than patients older than 65 years, but this difference was not statistically significant. There was no difference in HGSC survival in the groups of patients with grade 2 and grade 3 diseases. However, optimal surgical debulking and platinum sensitivity were associated with significantly better overall survival.

\section{References}

1. Vaughan S, Coward JI, Bast RC Jr, Berchuck A, Berek JS, Brenton JD, et al. Rethinking ovarian cancer: recommendations for improving outcomes. Nat Rev Cancer. 2011:11:719-25. https://doi.org/10.1038/nrc3144 PMid:21941283 PMCid:PMC3380637

2. Incidence and Mortality Worldwide: IARC Cancerbase number 11. Lyon, France: International Agency for Research on Cancer 2013. Available from: http://globocan.iarc.fr. Accessed April 2017.

3. National Cancer Institute. SEER (Surveillance, Epidemiology and End Results Program). SEER Cancer Fact Sheets: Cancer of the Ovary. Available from:

http://seer.cancer.gov/statfacts/html/ovary.html. Accessed April 2017.

4. du Bois A, Quinn M, Thigpen T, et al. 2004 consensus statements on the management of ovarian cancer: final document of the 3rd International Gynecologic Cancer Intergroup Ovarian Cancer Consensus Conference (GCIGOCCC 2004). Ann Oncol. 2005;16(Suppl 8):7-12. https://doi.org/10.1093/annonc/mdi961 PMid:16239238

5. Cannistra SA. Cancer of the Ovary. New Engl J Med. 2004;351: 2519-29. https://doi.org/10.1056/NEJMra041842 PMid:15590954

6. Lowe KA, Chia VM, Taylor A, et al. An international assessment of ovarian cancer incidence and mortality. Gynecol Oncol. 2013;130:107-14. https://doi.org/10.1016/i.ygyno.2013.03.026 PMid:23558050

7. Janssen-Heijnen ML, Houterman S, Lemmens VE, Louwman MW, Coebergh JW. Age and co-morbidity in cancer patients: a population-based approach. Cancer Treat Res. 2005;124:89-107. https://doi.org/10.1007/0-387-23962-6 5 PMid:15839192

8. Gulbech Ording A, Garne JP, Witt Nyström PM, Frøslev T, Toft
Sørensen $\mathrm{H}$, Lash TL. comorbid diseases interact with breast cancer to affect mortality in the first year after diagnosis - a Danish nationwide matched cohort study. PLoS One. 2013;8(10):e76013. https://doi.org/10.1371/journal.pone.0076013 PMid:24130755 PMCid:PMC3794020

9. Lee Y, Miron A, Drapkin R, Nucci MR, Medeiros F, Saleemuddin $A$, et al. A candidate precursor to serous carcinoma that originates in the distal fallopian tube. J Pathol. 2007;211:26-35. https://doi.org/10.1002/path.2091 PMid:17117391

10. Vang R, Shih leM, Kurman RJ. Ovarian low-grade and highgrade serous carcinoma: pathogenesis, clinicopathologic and molecular biologic features, and diagnostic problems. Adv Anat Pathol. 2009;16:267-82.

https://doi.org/10.1097/PAP.0b013e3181b4fffa PMid:19700937 PMCid:PMC2745605

11. Bowtell DD, Bohm S, Ahmed AA, et al. Rethinking ovarian cancer II: reducing mortality from high-grade serous ovarian cancer. Nat Rev Cancer. 2015;15:668-79.

https://doi.org/10.1038/nrc4019 PMid:26493647 PMCid:PMC4892184

12. Hainsworth JD, Grosh WW, Burnett LS, Jones HW 3rd, Wolf SN, Greco FA. Advanced ovarian cancer: long-term results of treatment with intensive cisplatin-based chemotherapy of brief duration. Ann Intern Med. 1988;108(2):165-70.

https://doi.org/10.7326/0003-4819-108-2-165 PMid:3124679

13. Neijt JP, ten Bokkel Huinink WW, van der Burg ME, et al. Longterm survival in ovarian cancer. Mature data from The Netherlands Joint Study Group for Ovarian Cancer. Eur J Cancer.

1991;27(11):1367-72. https://doi.org/10.1016/0277-5379(91)90011$\underline{2}$

14. Winter WE 3rd, Maxwell GL, Tian C et al. Prognostic factors for stage III epithelial ovarian cancer: a Gynecologic Oncology Group Study. J Clin Oncol. 2007;25(24):3621-7

https://doi.org/10.1200/JCO.2006.10.2517 PMid:17704411

15. Markman M, Lewis JL Jr, Saigo $P$ et al. Impact of age on survival of patients with ovarian cancer. Gynecol Oncol. 1993;49(2):236-9. https://doi.org/10.1006/gyno.1993.1113 PMid:8504993

16. Rabban JT, Bell DA. Current issues in the pathology of ovarian cancer. J Reprod Med. 2005;50(6):467-74. PMid:16050571

17. Silverberg SG. Histopathologic grading of ovarian carcinoma: a review and proposal. Int J Gynecol Pathol. 2000;19(1):7-15. https://doi.org/10.1097/00004347-200001000-00003

PMid:10638449

18. Singer G, Kurman RJ, Chang H-W, et al. Diverse tumorigenic pathways in ovarian serous carcinoma. Am J Pathol. 2002;160:1223-28. https://doi.org/10.1016/S0002-9440(10)62549$\underline{7}$

19. Vang R, Shih le M, Salani R, et al. Subdividing ovarian and peritoneal serous carcinoma into moderately differentiated and poorly differentiated does not have biologic validity based on molecular genetic and in vitro drug resistance data. Am J Surg Pathol. 2008:32:1667-74

https://doi.org/10.1097/PAS.0b013e31816fd555 PMid:18769340

20. Fader AN, Rose PG. Role of surgery in ovarian carcinoma. $J$ Clin Oncol. 2007;25(20):2873-83. https://doi.org/10.1200/JCO.2007.11.0932 PMid:17617518

21. Elattar A, Bryant A, Winter-Roach BA, Hatem M, Naik R. Optimal primary surgical treatment for advanced epithelial ovarian cancer. Cochrane Database Syst Rev. 2011;(8):CD007565. https://doi.org/10.1002/14651858.CD007565.pub2

22. Dao F, Schlappe BA, Tseng J et al. Characteristics of 10-year survivors of high-grade serous ovarian carcinoma. Gynecol Oncol. 2016;141(2):260-3. https://doi.org/10.1016/i.ygyno.2016.03.010 PMid:26968641 PMCid:PMC4844793 